\title{
Food and Water Consumption Completion Status
}

National Cancer Institute

\section{Source}

National Cancer Institute. Food and Water Consumption Completion Status. NCI

Thesaurus. Code C119838.

A term used to describe the state or condition of the completeness of the food and water consumption data. 